\title{
Flusser em Wuhan: por uma economia política da imagem técnica na iconomia do capitaloceno
}

\section{Gilson Liberato Schwartz}

Doutor; Universidade de São Paulo, São Paulo, SP, Brasil

schwartz@usp.br

\section{Resumo}

A contribuição de Vilém Flusser à emergência de novas epistemologias comunicacionais é sugerida como horizonte para a definição de uma iconomia ou teoria do valor econômico das imagens no capitalismo audiovisual antropocênico. Os elementos para essa aproximação partem da crítica flusseriana à sociedade do espetáculo e à fetichização dos ícones em seu texto Iconoclastia e em escritos de sua ficção filosófica aberta e voltada ao pensamento por jogos de imagens em que se destacam o fluxo, a liquidez, a maleabilidade e a adaptabilidade inteligente por meio de alegorias digitais oceânicas. Trata-se de valorizar as imagens usadas por Flusser como referência para uma teoria do valor capaz de superar a racionalidade instrumental binária que polariza o próprio pensamento econômico entre utilitaristas e materialistas.

\section{Palavras-chave}

Iconoclastia. Imagem técnica. Jogos de linguagem. Memória artificial. Imaginação.

\section{Os metaversos lúdicos da pós-história}

O registro de uma transformação civilizacional, de uma transição epocal (epochalen Übergang), de uma mudança de paradigma, constitui um aspecto determinante do legado de Vilém Flusser. Seja à "pós-história" (termo cunhado já em 1967), seja à "pós-modernidade" (antes que o "pós-moderno" virasse um novo modismo intelectual), Flusser faz alusão a um "novo clima existencial" em que o homem se assume como homo ludens e não mais como homo faber (HANKE, 2015). 
Trata-se de uma imaginação nova, cujas consequências eram ainda imprevisíveis mas já estavam associadas a um estruturalismo cibernético. 0 desafio é decodificar a epoché audiovisual. 0 mundo deve então ser penetrado por uma nova fenomenologia, ou seja, o momento disruptivo não é totalmente trágico pois traz em si novos desafios criativos e interpretativos. Mais recentemente, Bernard Stiegler vem solicitando uma perspectiva semelhante. Enquanto Flusser contrapõe a linearidade da escrita a uma nova lógica fluida que perpassa as superfícies e interfaces, Stiegler retoma os insights de Husserl e Simondon relativos às retenções temporais associadas à natureza farmacológica da técnica (TURNER, 2020).

Tanto Flusser quanto Stiegler tomam por objeto a mesma revolução, que é simultaneamente objetiva e subjetiva; ela é instaurada no campo fenomenal e ao mesmo tempo exige uma completa reconfiguração epistemológica, sem a qual se perde a própria potência transformadora e sem a qual o que pode ser remédio torna-se veneno mortal.

0 elemento essencial a reter aqui é o de transformação paradigmática e existencial, em que os processos comunicacionais se tornam vetores de alteração do modo de ser técnico no mundo. Automação e codificação tornam o fazer humano (Machen) cada vez mais próximo de uma poiesis de inspiração nietzschiana (Schaffen), uma estética da existência técnica (APOLINÁRIO, 2011). Como sublinha Hanke, a referência a "revolução" parece gasta pelo uso e abuso até mesmo em campanhas publicitárias, mas é disso que se trata na póshistória.

A emergência do neologismo iconomia em 2006 coloca o imperativo de aproximar a mudança tecnoexistencialista de uma nova perspectiva no horizonte da economia política, ou seja, da teoria do valor. O neologismo é usado por Peter Szendy (2017) e Michel Volle (2013): a força desse novo sentido é portanto uma evidência que se impõe em autores completamente independentes e até mesmo divergentes nas abordagens do novo fenômeno que aponta para as relações fluidas entre valor, imagem e imaginação na organização da inovação tecnológica e da representação espetacular do mercado como jogo.

A mesma busca de uma nova economia política foi realizada a partir de uma releitura de inspiração wittgensteiniana em $O$ capital em jogo: fundamentos filosóficos da especulação financeira: é a partir de jogos de linguagem, não do tempo espacializado e cartesiano do contraponto mecânico entre oferta e demanda, que se organizam os mercados e se configuram os sistemas de preços (SCHWARTZ, 2000). Em 2019, numa primeira 
abordagem, a "iconomia" é apresentada como crítica digital à economia industrial e financeira (SCHWARTZ, 2019).

Nosso propósito nesta breve reflexão é apresentar novas referências que permitam uma aproximação da contribuição flusseriana à economia política, apontando assim para um programa de pesquisa centrado na economia política da imagem técnica.

Os mercados são movidos por jogos de liquidez e variações inesperadas das preferências de consumidores, produtores e investidores. Esses jogos e variações ganham o estatuto de espetáculos em que as imagens podem ser interrompidas ou apagadas, ou seja, no limite o processo de acumulação de capital como imagem é também crise de representação.

Mas como indicar um limite a um processo cuja lógica é a acumulação, portanto a ausência de limites? Na tradição marxista, fortemente marcada pela dialética hegeliana, o problema lógico, estético, tecnológico e até mesmo existencialista de traduzir uma crise em oportunidade de superação nunca foi plenamente resolvido nem na teoria e menos ainda na prática. Quando ao panteão das crises tópicas associa-se a crise da imagem e da visibilidade como contradição própria à existência de cada indivíduo isolado, porém em rede é possível retomar, sobretudo a partir da digitalização civilizacional, as conexões entre crise de imagem ou crise de representação ao tema fundamental da crise da imaginação. Ou seja, uma crise que se manifesta tanto do ponto de vista estético quanto de suas implicações tecnoexistencialistas.

A visualização da nova etapa lógica e histórica da acumulação de capital como acumulação de imagens técnicas, é, portanto plenamente compatível com o objetivo de ampliar o horizonte flusseriano relativo à formulação e implementação de políticas econômicas voltadas à superação do capitaloceno.

Ou seja, trata-se de superar o determinismo clássico do marxismo e sem abdicar de uma visão progressista ou evolucionária da história humana dar a devida ênfase, no campo das políticas públicas e sobretudo das políticas econômicas, à imaginação produtiva (em oposição a uma destruição criativa), o que requer uma visão crítica do chamado antropoceno que tenha como referência uma teoria do valor consistente com a superação da crise contemporânea do modo de produção capitalista (MOORE, 2017).

A imaginação nova a que se refere Flusser quando aponta para a mudança epocal de paradigma em curso é também um desafio de ordem econômica e política. Num momento 
de catástrofe global e esgotamento das energias utópicas, há uma falência de todo fundamento do valor (seja utilitário, seja ricardiano-marxista).

As cadeias de valor mediadas pelas redes digitais tornam a acumulação de capital, ou seja, o processo mesmo de expansão dos mercados uma dimensão adicional da rizomatização das imagens. Além de oferta e demanda, a definição do preço requer uma imagem ou ícone de valor que permita o reconhecimento de uma transação.

A dimensão icônica do valor torna-se determinante, mas ao mesmo tempo implica na conversão de valores um processo sem fundamento (bodenlos, que não se prende a nenhuma base material fixa no espaço físico, nacional ou instrumental). Diante da crise de representação e da simultânea inflação imagética, torna-se ainda mais patética a busca de soluções supostamente eficientes de superação da crise global por meio do livre funcionamento das forças de mercado, da racionalidade corporativa ou mesmo do planejamento estatal. As tais forças, racionalidade e planejamento podem literalmente passar a não fazer sentido para investidores, cidadãos, empresários, trabalhadores e famílias.

Em suma, a partir da percepção vanguardista de uma pós-história comandada pela nova imaginação tecnoexistencialista centrada nos processos comunicacionais, buscamos integrar a perspectiva flusseriana a um programa que, nos anos 1960/1970, ainda engatinhava, mas agora se tornou imperativo: uma integração da mudança de paradigma tecnológico aos limites ecológicos e culturais da expansão capitalista em escala global.

Aliás, pode-se dizer que essa explicitação da dimensão ao mesmo tempo técnica e imagética do funcionamento dos mercados também tem implicações críticas sobre a formulação e implementação de políticas econômicas no sentido estrito (seja de curto prazo no campo monetário e fiscal, seja no desenvolvimento no longo prazo por meio de investimentos públicos e privados). Ocorre que mesmo o quadro de referência dessas políticas públicas requer fundamentos supostamente sólidos que, no entanto, são decorrentes da acumulação sempre e apenas imaginária de capitais simbólicos e expectativas mais ou menos desgarradas.

Esse programa de pesquisa, que tem origem na economia política, acompanha assim a partir das ideias de Flusser uma nova percepção da transformação econômica digital que é centrada na compreensão dos metaversos imaginários da pós-história dos mercados. Ocorre que esse potencial também estava presente no pensamento pioneiro e no legado intelectual e humanista de Flusser, sob a forma de uma ficção filosófica que é também um jogo de 
linguagem e um exercício lúdico-existencialista que se materializou em sua criativa oceanologia digital, a partir de uma deriva ensaística em torno do animal marítimo Vampyroteuthis Infernalis.

É surpreendente a atualidade da sua escrita ensaística, que, sob a forma de uma ficção filosófica, antecipa nosso mundo contemporâneo, perplexo e tragicamente aprisionado por uma pandemia cuja origem é apontada justamente na hiperexploração mercantil de animais silvestres, especialmente marinhos, no aparentemente distante polo hipercapitalista de Wuhan.

\section{Considerações metodológicas}

O legado de Flusser inspira possíveis convergências entre a crítica cultural à inovação tecnológica, a economia política do antropoceno e a renovação do projeto hermenêutico de uma ação comunicativa criativa e livre. Metodologicamente, é importante notar que sua abordagem parte da crítica aos limites entre ciência e ficção, entre racionalidade e imaginação, seja na formulação dos conceitos, seja no planejamento de ações públicas.

O que propomos a partir de Vilém Flusser é ir além da descrição da transformação epocal como etapa pós-histórica, ou seja, como uma entrada em arco civilizacional e existencial que se define negativamente com relação à escrita linear e espacializante, e dar o passo seguinte, que é dar a essa emergência pós um novo nome próprio, como iconomia. A iconomia é a esfera de organização do tempo, da linguagem e da identidade em uma rede de projetos. Não se trata de uma nova utopia, mas de passar a conceber uma diversidade de regimes de imaginação/acumulação de capitais criativos na produção, no consumo e na própria iconicidade. Esse é o passo que permitirá também questionar a funcionalidade dominante da moeda e das finanças, propondo-se que sejam compatíveis com a superação pós-romântica da destruição criadora do antropoceno.

A integração entre economia política, filosofia da linguagem e a redescoberta de uma filosofia/estética da natureza talvez seja irrealizável enquanto sistema teórico-filosófico (algo que o próprio Flusser nunca pretendeu), mas a retomada das questões clássicas da economia política na perspectiva dos fluxos líquidos da imagem técnica flusseriana abre caminhos para uma revisão do que se fez e se pode fazer no mercado, no Estado e na sociedade. 
É uma nova era que se abre para uma libertação de caráter dialógico e não utilitarista ou determinista; portanto, não sendo mecânica nem teleológica, permite a emergência de elaborações desnecessárias da informação pura num jogo de ressignificação que se pode denominar lúdico.0 jogo de linguagem na concepção wittgensteiniana é o ponto de partida para essa esf(era) lúdica. No horizonte dos artefatos, interfaces e plataformas desse capitaloceno digital, a gamificação é um processo exemplar desse potencial farmacológico das tecnologias da informação. A gamificação da teoria do valor é uma decorrência da perspectiva flusseriana que se presta a uma metaversalização da economia política das imagens técnicas.

Nesse sentido, procuramos escapar tanto do economicismo quanto do comunicacionalismo, identificando a revolução flusseriana à emergência de novas organizações das relações entre Estado, mercado e sociedade, mediadas por redes e jogos de valor impulsionados pela fruição iconômica.

\section{Iconomia dos oceanos digitais}

Há um tema que percorre a obra de Vilém Flusser desde os anos 1960, a idolatria. É crucial nesse exercício de aproximação à "iconomia" que se reconheça essa fundação, pois a partir daí toda e qualquer análise das imagens técnicas tem como corolário uma dimensão ideológica e mesmo religiosa (RESTUCCIA, 2018). Está em jogo a formulação de uma teoria contemporânea da idolatria, a começar da idolatria do Capital, pensada a partir de uma releitura teológico-política que atualiza a crítica judaico-marxista à adoração de imagens de valor na era da tecnoimaginação, em que a circularidade do tempo mágico dá lugar a novos modelos de imaginação codificada. Da mais-valia à mais-magia.

Da consciência histórica à magia crítica e pós-histórica, há todo um aparato e uma massa de funcionários para organizar, controlar e promover. 0 desafio que a atualidade nos lança, na visão de Flusser, é submeter as novas imagens à análise racional e transformá-las em instrumentos de ação histórica em vez de permitir que funcionem como superfícies adoradas.

Podemos, a partir desse posicionamento, traçar um programa de pesquisa para a iconomia. 0 caminho para estabelecer essa conexão, no entanto, passa pela recuperação da própria imaginação ou ficção filosófica de Flusser, em que o horizonte da relação entre 
natureza e cultura se altera de modo ficcional. Encontramos essa referência/provocação em Vampyroteuthis Infernalis - acompanhamos aqui as indicações de Felinto (2018).

O elo fundamental na construção da iconomia flusseriana é o conceito de memória. É na diferenciação entre competências mnemônicas que se diferencia o animal superior do inferior. A memória no animal superior já não se dá na dimensão da reprodução, mas da criação de projeções mnemônicas; ou seja, todo lugar de memória é a projeção de uma geração futura e não apenas a reprodução de uma informação que viria de um tempo pretérito.

Nos humanos, portanto, a transmissão de informação é um processo cumulativo e aberto à evolução criativa. É acumulação de capital simbólico, ou seja, ampliação da produção material, que é indissociável de uma expansão icônica que, no dinheiro, assume o caráter de entidade sobrenatural, como ídolo ou adoração. 0 problema central da memória é o mesmo da arte e, afinal, da religião: criar métodos para fabricar memórias artificiais, a partir de agora em rede.

O polvo é a metáfora biológica para um tertius, uma possibilidade que vai além da oposição entre animais inferiores (transmissão genética da informação) e superiores (registro inanimado e sujeito à deterioração em objetos exteriores nos quais a informação é codificada), porque a arte do ser social Vampyroteuthiano consiste numa ejaculação de cores, um orgasmo artístico em que é a superfície da pele, é o próprio corpo que se contrai e secreta pigmentos em reação à percepção de informação nova, que, assim, é transmitida a outros seres vivos horizontalmente (não a objetos inanimados, nem à descendência biológica). É a transformação autocriativa que anima o encontro propício ao acasalamento e à procriação cumulativa. A reprodução torna-se uma conversação. No lugar da mais-valia, mais-magia.

O que perdemos é uma modalidade de dependência materialista que durou séculos, deixou arquivos e ciências como herança, mas não parece mais suficiente diante da multiplicação contemporânea de memórias artificiais. Há nessa pluritecnológica memória social modalidades cada vez mais abertas e flexíveis de criar, reter e recombinar a memória artificial. Por isso tornamo-nos tão parecidos com polvos e seus multicérebros perceptivos.

A rede e nossa inserção vital nela é construída a partir de novas modalidades, texturas, superfícies e territórios onde as mediações virtuais que resultam do hibridismo material e digital abre novos horizontes imateriais e intersubjetivos. 
No software, assim como na guerra cultural disputada por soft powers, a dimensão soft equivale às estratégias criativas líquidas, maleáveis ou moles como o corpo de um polvo, visualizadas na reprodução de moluscos, na qual predomina a contração e secreção de cromatóforos, ou seja, estamos diante de uma economia política audiovisual.

O que está em jogo nas metáforas da oceanografia digital flusseriana? A questão de fundo é a tradução, ou seja, a questão de como se movimentar entre diferentes culturas ou esferas culturais. No limite está colocada a questão do "trânsito entre as estruturas da razão e do imaginário" (FELINTO, 2018, p. 111). Na iconomia, trata-se de abraçar, sugar e modelar-se de acordo com todos os objetos materiais possíveis, dando-lhes novas utilidades e reinventando as relações entre energia, trabalho e consumo.

Essa transformação da memória em processo biopolítico que instaura uma zona cinzenta representa possivelmente a perspectiva epistemologicamente mais fecunda da ficção filosófica flusseriana. A “[...] estratégia consistiria em atravessar por inteiro o ficcional para ali encontrar o não ficcional" (FELINTO, 2018, p. 112), desenvolvendo uma teoria do valor econômico que ultrapassa a busca de fundamentos no utilitarismo ou na exploração material do trabalho, ou seja, uma perspectiva em que se fala abertamente da falta de fundamento objetivo em cada processo valorativo da iconomia.

O valor é resultado dessa aposta da imaginação, não da exploração ou da transferência espacial de materiais, mas de uma especulação com espetacularização cujas relações com as bases materiais da produção ou da troca serão sempre e inevitavelmente problemáticas, ainda que nem sempre catastróficas ou condenadas à desregulação esquizofrênica do hiperliberalismo.

A iconomia enquanto economia política de imagens técnicas virá a ser, portanto, uma economia com capacidade imaginativa, um sistema aberto e vampyrotheutiano eletromagnético ordenado com a fluidez dos moluscos por meio de softwares jogáveis.

\section{Flusser em Wuhan (in/conclusão)}

O consumo de animais silvestres, sobretudo de animais marítimos, mas também de morcegos e outras espécies, aparece hoje como uma fronteira viral que ameaça a própria reprodução ampliada do capital. A ficção científica-filosófica torna-se mais real, e a alegoria 
flusseriana dos cefalópodes como antípodas a partir dos quais podemos perceber os limites do capitalocento ganha todo o sentido.

Estamos novamente diante do caráter precário, vulnerável e volátil do código genético e da necessidade de outras formas de comunicação intervitais sob o risco de sucumbirmos à hiperexploração que leva ao consumo irrefreado, porta de entrada para a morbidade viral.

Se é fato que a obra de Flusser nos convida a repensar a arte, os códigos e o imaterial, sua ficção crítica ganha atualidade emergencial quando traduzida em termos biopolíticos e quando a economia política do capitaloceno vem para primeiro plano. Esse é o horizonte interpretativo aberto pela leitura de Flusser, convidando o leitor contemporâneo a um perspectivismo em que o morcego de Wuhan seja nosso irmão e jamais nosso indomável algoz.

\section{Referências}

APOLINÁRIO, J. A. F. Práxis como poiesis em Nietzsche. Estudos Nietzsche, Curitiba, v. 2, n. 2, p. 185-205, 2011.

FELINTO, E. Oceano digital: imaginário marinho, tecnologia e identidade em Vilém Flusser. Galáxia, São Paulo, n. 39, p. 110-123, 2018.

HANKE, M. M. Pós-História e Pós-Modernidade. Dois conceitos-chave da filosofia da cultura crítica de Vilém Flusser e sua análise contemporânea da mídia e das imagens técnicas.

Galáxia, São Paulo, n. 29, p. 96-109, 2015.

MOORE, J. W. The Capitalocene, Part I: on the nature and origins of our ecological crisis. The Journal of Peasant Studies, [s.l.], v. 44, n. 3, p. 594-630, 2017.

RESTUCCIA, F. Flusser against Idolatry. Flusser Studies, Roma, n. 26, p. 1-15, 2018.

SCHWARTZ, G. 0 capital em jogo: fundamentos filosóficos da especulação financeira. Rio de Janeiro: Campus, 2000.

SCHWARTZ, G. Iconomia: introdução à crítica digital da economia industrial e financeira. Salvador: EDUFBA, 2019.

SZENDY, P. Le Supermarché du visible: essai d'iconomie. Paris: Les Editions de Minuit, 2017.

TURNER, B. Politicising the Epokhé: Bernard Stiegler and the politics of epochal suspension. In: APOSTOLESCU, I. (ed.). The Subject(s) of Phenomenology: rereading Husserl. [s.l.]: Springer, 2020.. 
VOLLE, M. Iconomie. Paris: Xerfi-Economica, 2013.

\title{
Flusser in Wuhan: towards a political economy of the technical image in the iconomy of the anthropocene
}

\begin{abstract}
Vilém Flusser's contribution to the emergence of new communicational epistemologies is suggested as a horizon for the definition of an iconomy, or theory of the economic value of images under Anthropocene audiovisual capitalism. The support for this approximation comes from the Flusserian critique of the society of the spectacle and of the fetishization of icons in his text entitled Iconoclastia ('Iconoclasm') as well as in his writings of open philosophical fiction dealing with thinking through image games in which flow, liquidity, malleability and intelligent adaptability come to the fore as digital oceanic allegories. It is time to appreciate the images used by Flusser as a reference for a new theory of value that will overcome the binary instrumental rationality that causes radical polarities between utilitarian and materialist economic thought.
\end{abstract}

\section{Keywords}

Iconoclasm. Technical image. Language games. Artificial memory. Imagination.

Recebido em 30/04/2020

Aceito em 09/06/2020 